\title{
Cognition and Practice of Innovative Education in Higher Education
}

\author{
Suting Zhang \\ NanChang Institute of Science \& Technology, Nanchang,330108
}

\author{
Keyword: Hierarchical Interaction; Highermathematics; Teaching mode; Practical exploration
}

\begin{abstract}
Under the background of rapid development of information technology, learning patterns are increasingly diversified. It can be said with certainty that the teaching mode of class instruction originally adopted by the education community is bound to enter a revolutionary era of great change. The education model will closely integrate with the network and information technology and many other new technologies together continue to break the traditional restrictions, fast forward. The current teaching model is too old, long-term infused teaching makes students accustomed to dull learning, classroom has inefficiency, ignoring innovation in teaching, especially in the context of Chinese culture, the lack of the training of innovative personnel of innovative top international innovation, that is, lack of method innovation to train students. Therefore, it is important to change the old traditional teaching mode, construct a new and effective teaching mode, improve the quality and reduce the burden, liberate the students, enable the students to learn effectively and lay the foundation for the students' lifelong development. This article focuses on the development of higher mathematics to explore the structure of interactive level teaching model.
\end{abstract}

\section{Introduction}

Under the background of big data era and the social situation that the knowledge-based economy is becoming the driving force of social development, the cultivation of innovative talents has become the focus of national development. The attention given by the state is also unprecedented. There are even slogans as follows: Innovation is the soul of the progress of the nation and innovation is the driving force behind the prosperity. Lack of innovation, especially in the context of Chinese cultural traditions, and lack of innovation in the international top-notch training of innovative personnel, lack of methods to foster student to obtain innovation ability. The 21 st century is the information society, innovative learning, information learning is a loud slogan, we must reform the traditional teaching mode. The existing teaching model is too old, long-term infused teaching makes students accustomed to mechanically learning, classroom is inefficiency, neglect innovation, therefore, the ability of students can't be cultivated. This article based on higher mathematics interactive teaching to make anunderstanding and discussion, research higher mathematics education mode.

\section{The Existing Problems in Higher Mathematics Teaching}

In the new era background, in order to speed up the process of higher education reform, we must thoroughly study and recognize the new requirements and new situation of higher education, always adhere to the people-oriented education concept, strictly follow the law of education reform, and carry out overall quality and comprehensive education to effectively improve the overall level of higher education. In this process, certain contradictions and problems will inevitably occur:

The Problem of Education Resources Allocation .Education has shifted from the allocation of hardware resources to the internal transformation and self-transformation of the system, from epitaxial development to connotative development and independent development, entering the stage that autonomicallybuild up school development direction, self-discipline school development characteristics, consciously inherit and cultivate a unique school culture. During this period, "differences" and "characteristics" should become indispensable elements of the lively and vivid development of ordinary higher education. 
The Basic Concepts for most Teachers Did not Change, the Basic Role Did not too. Teachers are still the main body of the class; speaking too much, students passively accept knowledge, the direct expression is "arranged by teachers instead." On the surface, the students are the main body and the teachers are the dominant ones. However, in the actual teaching, teachers' "dominance" still plays an absolutely dominant role and the teachers still become the center. The teachers become painful, while the students feel not good to learn, Teacher said: "I've told you a hundred times, why did you still not know it?" Students answer: "When you talk about it, I will understand it, but whenI do it, it will not work!"

Single Teaching Mode, Rigid, Dull, no Motivation. "Teaching, there is no" exploration "," no practice ", with low efficiency." Learning "is still subject to" teaching ", teachers take teaching as the main body, whilestudent starts to learn after getting the teacher's teaching, they don't know to learn it by themselves.

\section{Interactive Teaching Mode}

Interactive teaching mode is student-centered, students are regarded as the main body of information processing, and teachers are required not only to impart knowledge to students, but also to promote student self-learning, active learning and have good interaction with students, which is the present stage where Europe and the United States those developed countries generally respected and adopted teaching model.

The interactive teaching mode is a well-planned and designed teaching method. Through comprehensive utilization of various teaching media, students are encouraged to innovate independently, think actively, and enhance communication and mutual promotion between students and teachers so as to foster students' exploration and discovery ability to solve problems and promote the overall quality of students.

The mutual promotion between students and teachers is mainly manifested in that the students' cognition of subjects and the dominant lectures of teachers complement each other, that is, enhancing the interaction between "teaching" and "learning". Through the effective regulation of the relationship between teachers and students, the formation of a harmonious teaching environment and harmonious teaching atmosphere, to promote effective interaction between teaching agents and learning individuals, and enhance the positive role of people and the environment on teaching in order to achieve teaching resonance and higher efficiency.

\section{Interactive Teaching Application Value}

Create a Turning Point for Innovation: Cultivate the Students' Awareness of the Subject, Create a Sound and Complete Personality. Each student is an independent life individual, has his own way of thinking, his own emotional and his personality traits. The purpose of education is for the development of students, education should make students truly become masters of learning. Through a variety of interactive forms, teachers can create innovative opportunities to introduce open-ended teaching methods such as discussion style, dialogue style, debating style, speech style and performance style into the classroom.

Improve Teaching Art: to Stimulate Students' Potential Cognitive Interest and Enhance the Sense of Success. Cognitive interest, also known as "curiosity," is the most realistic and active component of student motivation. Tolstoy said that successful teaching is not mandatory, is to fully mobilize the enthusiasm of students involved in the interest to become the best teacher to learn. Proper use of teaching situations to create situations, set suspense method, starting from the students to stimulate potential cognitive interests, often can receive good results.

Expand Teaching Space and Time: Cultivate Students' Practical Awareness, Develop a Theory-based Learning Style. Classroom teaching system is open, developing, not closed or static. Classroom teaching should break the concept of self-enclosed, establish the combination of inside and outside the class, combine inside and outside of the school, and combine theory with practice. It is necessary to solve the problems of "unknown" and "knowledge", "knowledge" and "energy", "disbelief" 
and "faith" and "line" and many other conflicts. The use of interactive teaching can expand teaching space and effectively solve the above contradictions.

\section{The Implementation of the Three Major Strategies in Level interactive Classroom Teaching}

Build Up the Shape and Construction. Through the study and training, demonstration and guidance, discussion and exchange, diagnosis and interpretation, the basic mode of "Interactive Teaching in Hierarchy" is established, and the basic requirements onteaching modes for case study, self-guidance, exhibition and exchange, study report implementation and team building are put forward, and strive to make the teaching model not only in line with the teaching laws, but also more in accord with the actual teaching and practice, when pursuit of scientific teaching, but also strengthen the mode of maneuverability and effectiveness.

The Second Step to Refine Requirements and Deepen the Connotation. Through elaborating the requirements, we can enhance the connotation of "interactive classroom" and enhance teachers' teaching skills through comprehensive evaluation so that most teachers are not constrained by the model but can understand the deeper teaching thoughts in the model so that" Level interactive classroom "have the shape and spirit.

Extension to Improve Quality.Study group is the basic unit of independent study, but also the basis for class self-management; scientific research group is the organization that instruct class subject learning, is also an effective carrier of school research learning; the executive group is the self-government organization of class management and the backbone of school management power.

\section{Conclusion}

The level interactive teaching requiresteachers must have a strong sense of responsibility and a certain degree of classroom teaching and control ability. The teacher who implements the level interactive teaching strategy is not necessarily the best teacher, but must be a qualified teacher who is accountable to the student. This responsibility is reflected in the correct comprehension and grasping of the curriculum standard and teaching materials as embodied in the proficiency in the application of subject knowledge and professional skills, showed in the management of classes and the organization of teaching and so on, which is important premise and necessary protection for level interactive teaching. Therefore, the implementation of interactive teaching strategies require teachers to strive to update their own ideas and recognize the differences between students, but also see the potential of students, respect the dominant position of students, allow students to choose according to the existing goals and encourage students constantly to improve themselves. The specific method of implementing the interactive teaching model at different levels must pay attention to avoiding the"different content with one teaching mode" and encouraging teachers to develop their own characteristic teaching methods based on their own personality, teaching style and teaching ability.

\section{References}

[1] Zou B. Analysis on Current Situation and Countermeasure of Higher Mathematics Teaching Based on Anhui Continuing Education Online[J]. Journal of Anhui Radio \& Tv University, 2017.

[2] Hui L I. The effective application of stratified teaching in higher mathematics teaching[J]. Journal of Liaoning Teachers College, 2016.

[3] Miao P, Fan L J. Analysis higher mathematics teaching mode based on discrete Hopfield neural network[J]. Journal of Science of Teachers College \& University, 2016.

[4] Wang Y, Mathematics D O. Application of Micro Division of Medical Higher Mathematics Teaching in the Micro Era[J]. China Continuing Medical Education, 2016.

[5] Yang X. On the Application of Formative Assessment to Higher Mathematics Teaching in Higher Vocational Colleges[J]. Science Education Article Collects, 2017.

[6] Liu S, Zhou F, Wang W, et al. On Application of Higher Mathematics Teaching Aided by 
Mathematical Software[J]. Journal of Xiangnan University, 2017.

[7] Yuan Q Q, Qin C L, Zhang C, et al. Exploration about integrating the history of mathematics into higher mathematics teaching[J]. Journal of Science of Teachers College \& University, 2017.

[8] Wang J, Amp A F. Exploration on the reform of higher mathematics teaching based on Modeling[J]. Journal of Hunan City University, 2016.

[9] Luan M, Zhang H, Cui G, et al. Research of higher mathematics teaching based on Matlab software[J]. Journal of Shenyang Normal University, 2017.

[10]Lu G. Application of Definite Integral in Higher Mathematics Teaching[J]. Modern Computer, 2015.

[11]Tian X, University B. Application Research on MES Module Teaching Method in the Teaching of Higher Mathematics[J]. Guide of Science \& Education, 2017.

[12]Tong D M. Application research to assist higher mathematics teaching based on Matlab[J]. Journal of Fuyang Teachers College, 2015. 